\title{
The mammalian circadian clock gene Per2 modulates cell death in response to oxidative stress
}

\author{
Maria Chiara Magnone $^{t \neq}$, Sonja Langmesser ${ }^{t \neq}$, April Candice Bezdek, Tiziano Tallone $^{\dagger}$, Sandro Rusconi ${ }^{\dagger}$ \\ and Urs Albrecht*
}

Department of Biology, Division of Biochemistry, University of Fribourg, Fribourg, Switzerland

Edited by:

Roland Brandstaetter, University of

Birmingham, UK

\section{Reviewed by:}

Axel Steiger, Max Planck Institute of

Psychiatry, Germany

Mitsuyuki Nakao, Tohoku University, Japan

\section{*Correspondence:}

Urs Albrecht, Department of Biology,

Division of Biochemistry, University of

Fribourg, Chemin du Musée 5, 1700

Fribourg, Switzerland

e-mail:urs.albrecht@unifr.ch

\section{${ }^{\dagger}$ Present address:}

Maria Chiara Magnone, CVMD iMed,

Astrazeneca R\&D, Mölndal, Sweden,

Sonja Langmesser, Medcept Ltd,

Meggen, Switzerland;

Tiziano Tallone, Cardiocentro Ticino,

Lugano, Switzerland;

Sandro Rusconi, Divisione della

cultura e degli studi universitari,

Dipartimento dell'educazione, della

cultura e dello sport, Repubblica e

Cantone Ticino, Bellinzona,

Switzerland

${ }^{\ddagger}$ Maria Chiara Magnone and Sonja

Langmesser have contributed equally

to this work.
Living in the earth's oxygenated environment forced organisms to develop strategies to cope with the damaging effects of molecular oxygen known as reactive oxygen species (ROS). Here, we show that Per2, a molecular component of the mammalian circadian clock, is involved in regulating a cell's response to oxidative stress. Mouse embryonic fibroblasts (MEFs) containing a mutation in the Per2 gene are more resistant to cytotoxic effects mediated by ROS than wild-type cells, which is paralleled by an altered regulation of $b c /-2$ expression in Per2 mutant MEFs. The elevated survival rate and alteration of NADH/NAD ${ }^{+}$ ratio in the mutant cells is reversed by introduction of the wild-type Per2 gene. Interestingly, clock synchronized cells display a time dependent sensitivity to paraquat, a ROS inducing agent. Our observations indicate that the circadian clock is involved in regulating the fate of a cell to survive or to die in response to oxidative stress, which could have implications for cancer development and the aging process.

Keywords: apoptosis, adenovirus, bcl-2, paraquat, plumbagin, UV, SIN-1, p53

\section{INTRODUCTION}

Life on earth is under the continuous influence of a light and dark cycle that is caused by the rotation of the earth around its axis and its orbit around the sun. Many organisms have internalized the cyclic change of light and darkness in the form of the circadian clock. This enables them to predict dusk and dawn giving them an edge in competing for limited resources and avoiding predators $(1,2)$. The circadian timing system provides a temporal organization within an organism to modulate and synchronize biological functions in order to prevent the activation of biochemical pathways that would counteract each other. During the day, catabolic processes facilitate engagement with the environment, whereas at night, anabolic functions of growth, repair, and consolidation predominate (3).

The mechanism underpinning the circadian clock is found in most cells of the body including fibroblasts (4). It comprises a set of clock genes that are organized in a positive and a negative limb constituting an autoregulatory feedback loop. The positive limb involves CLOCK:BMAL1 heterodimers that bind to E-box promoter elements located in the regulatory region of the Period (Per1, Per2) and Cryptochrome (Cry1, Cry2) genes. Their proteins form oligomers that are transported from the cytoplasm to the nucleus where they repress their own transcription (negative limb) (5). The positive and negative limbs are interlaced by the nuclear orphan receptor REV-ERB $\alpha$ repressing transcription of Bmall through binding to a RORE element present in the Bmall promoter (6). Interestingly, the molecular clock components do not only influence their own transcription but also regulate the expression of a large number of genes belonging to diverse biochemical pathways. Clock regulated key pathways include detoxification, oxidative phosphorylation, and energy metabolism $(7,8)$. Therefore, one could expect that an organism with a defective circadian clock would have difficulties in coping with environmental stress. This view is supported by the finding that mice mutant in the Per2 gene $\left[\right.$ Per ${ }^{\text {Brdml } 1}$, Ref. (9)] are cancer-prone after $\gamma$ irradiation (10). The effects of this DNA damaging treatment might also be related to abnormal responses of $\mathrm{Per} \mathrm{B}^{\mathrm{Brdm} 1}$ mutant cells to oxidative stress.

Oxidative stress can be caused by intra- or extracellular sources of reactive oxygen species (ROS), such as $\mathrm{O}_{2}$ radicals, which are produced in mitochondria during oxidative phosphorylation or are generated due to genotoxic stress by agents such as paraquat. In a cell, oxidative stress affects the production of low 
molecular mass antioxidants (e.g., vitamin C, tocopherol, lipoic acid) and the induction as well as the activation of antioxidant enzymes, such as catalase, glutathione peroxidase, and superoxide dismutases (SODs). A disturbance of the balance between pro-oxidant:antioxidant processes leads to alterations in redox homeostasis and oxidation of DNA and cellular biomolecules. In a first line, the cell may respond by autophagy, in order to remove damaged cellular components and damaged organelles. Alternatively, the cell can undergo either necrotic cell death or programed cell death (apoptosis). However, the switch between the different possibilities for a cell to respond to oxidative stress is not completely understood [reviewed in Ref. (11)].

Since the circadian clock integrates and regulates metabolism, we started to investigate whether the circadian clock is involved in cellular response to oxidative stress. In particular, we were interested in the role of the Per2 gene, which is known to be one of the clock components responding to external signals such as light (12) and temperature (13). We found that at the cellular level Per2 is involved in the response of a cell to oxidative stress.

\section{EXPERIMENTAL PROCEDURES}

\section{ISOLATION OF MOUSE EMBRYONIC FIBROBLASTS}

Mouse embryonic fibroblasts (MEFs) from wild type and Per $2^{B r d m 1}$ mutant mice were obtained at E13.5-14. Embryos were dissected under sterile conditions, the heads and the internal organs were discarded, and the rest of the bodies were minced and passed through a $2 \mathrm{ml}$ bent syringe into a $60 \mathrm{ml}$ bottle. Embryos were incubated in $5 \mathrm{ml}$ trypsin $/ 2 \mathrm{mM}$ EDTA at $37^{\circ} \mathrm{C}-5 \% \mathrm{CO}_{2}$ for $15 \mathrm{~min}$, pelleted ( $4000 \mathrm{~g}$ for $5 \mathrm{~min}$ ), resuspended in $10 \mathrm{ml}$ of fresh DMEM $+10 \%$ FCS, and plated in $60 \mathrm{~mm}$ dishes (1:5 dilution). The next day, the medium was removed the plates were rinsed twice with TBS and covered with $10 \mathrm{ml}$ of fresh medium. The plates were then incubated for $24 \mathrm{~h}$ at $37^{\circ} \mathrm{C}-5 \% \mathrm{CO}_{2}$ and split 1:10. About $90 \%$ confluent MEF's were frozen in FCS $+10 \%$ DMSO and stored in liquid nitrogen until used. At least three cell lines for every genotype were obtained and tested for paraquat sensitivity.

\section{ENZYMATIC ASSAYS}

Cells (passage 4-5) were cultured in DMEM/10\% FCS until confluency was reached, then trypsinized and collected for the enzymatic assays (ca $6 \times 10^{6}$ cells). The aconitase assay was performed according to Gardner et al. (14). The SOD assay was done according to the manufacturers instruction in the Trevigen kit (order \# 7500-100-K). Lactic dehydrogenase (LDH) assay was performed according to Gardner et al. (15). Cell homogenates were prepared in ice-cold PBS pH 7.4 as described above. The assay was performed in $200 \mu \mathrm{l}$ reaction mixture containing $50 \mathrm{mM}$ PBS, $\mathrm{pH}$ 7.4, $50 \mu \mathrm{l}$ of sample, $0.2 \mathrm{mM} \mathrm{NADH}$, and $1 \mathrm{mM}$ sodium pyruvate. The decrease in absorbance at $340 \mathrm{~nm}$ was recorded for $3 \mathrm{~min}$ at $25^{\circ} \mathrm{C}$ and correlated to $\mathrm{LDH}$ activity using a standard curve. $\mathrm{LDH}$ activity was normalized for the protein amount.

Total NADH/NAD ${ }^{+}$ratio in cell extracts was estimated by the lactate/pyruvate ratio $(16,17)$. Lactate and pyruvate were measured in whole cell extracts (ca $6 \times 10^{6}$ cells) of wild type and Per $2^{B r d m 1}$ mutant cells synchronized by a $100 \mathrm{nM}$ dexamethasone shock (see last paragraph) and taken $6 \mathrm{~h}$ after the shock. The samples were tested for lactate and pyruvate levels by adding to the reaction mixture (glycine buffer $\mathrm{pH} 10.0,25 \mu \mathrm{l}$ of sample and 10 units of lactate dehydrogenase) $0.2 \mathrm{mg}$ of $\mathrm{NAD}^{+}$or $\mathrm{NADH}$, respectively. The increase or the decrease in absorbance at $340 \mathrm{~nm}$ was recorded after $15 \mathrm{~min}$ and correlated to lactate and pyruvate concentration through standard curves. Values were calculated using the formula in Ref. (16) with $K_{\mathrm{eq}}=4.4 \times 10^{-2}$. Complex I activity was measured according to Chretien et al. and Klement et al. $(18,19)$.

\section{PARAQUAT, PLUMBAGIN, HYDROGEN PEROXIDE, SIN-1, AND UV LIGHT TREATMENTS}

Mouse embryonic fibroblasts were treated with paraquat (Supelco, PS-366), plumbagin (Sigma P7262), SIN-1 (Sigma M-5793), and hydrogen peroxide (Sigma H-1009) as reported in Ref. (20) or treated with ultra-violet (UV) light. Briefly, cells were plated in DMEM-10\%FCS until confluent and then seeded in 96-wells plates (3000-5000 cells/well). The day after the medium was replaced and paraquat and $\mathrm{H}_{2} \mathrm{O}_{2}$ were added at different concentrations $(0,200,400,600,800,1000 \mu \mathrm{M}$, total volume $150 \mu \mathrm{l})$. Plumbagin was added at a final concentration of $1.5 \mu \mathrm{M}, \mathrm{SIN}-1$ at a concentration of $2 \mathrm{mM}$, or cells were exposed to UV light at $120 \mathrm{~mJ} / \mathrm{cm}^{2}$. After $24 \mathrm{~h}$, the cytotoxic effect was measured by a commercial kit based on the colorimetric determination of the $\mathrm{LDH}$ released upon cell lysis (Promega, $\neq$ G-1780). The cytotoxicity was evaluated by calculating the ratio between the $\mathrm{LDH}$ released spontaneously and the total LDH contained in the cells and expressed as percentage of cytotoxicity (dead cells relative to the total number of cells). The rescuing of paraquat cytotoxicity through $\mathrm{N}$-acetyl-cysteine (NAC) was performed according to Macip et al. (21) using $50 \mu \mathrm{M}$ NAC.

\section{CRYSTAL VIOLET STAINING}

Cells were seeded into 24 well plates $\left(4 \times 10^{4}\right.$ cells/well $)$ and treated with paraquat, NAC, or paraquat + NAC for $24 \mathrm{~h}$ (see above). Medium was aspired; cells were washed once with PBS and incubated with $0.02 \%$ crystal violet $/ 2 \% \mathrm{EtOH}$ for $20 \mathrm{~min}$ at room temperature. Plates were thoroughly rinsed with tap water and dried. Crystal violet was solubilized in 1\% SDS, and sample absorption was read at $595 \mathrm{~nm}$.

\section{CONSTRUCTION OF A RECOMBINANT ADENOVIRUS EXPRESSING THE FULL LENGTH Per2 ORF (Ad-Per2)}

The Per2 gene, cloned into a Tet-repressible expression vector (pSCOT), was inserted into the E1 region of a cloned $\triangle \mathrm{E} 1 \Delta \mathrm{E} 3$ adenoviral backbone (vmRL-CMV1) through homologous recombination in E. coli BJ5183. Bacteria were transformed by electroporation $(2.5 \mathrm{kV}$ in $0.2 \mathrm{~cm}$ gap cuvettes, $25 \mu \mathrm{F}, 200 \Omega$ ) with the vector carrying the Per 2 gene and the virus mid. Both constructs were carrying the CMV promoter and a region spanning the rabbit $\beta$-globin intron 2 and the $\beta$-globin exon 3 , where the homologous recombination occurred. Positive clones were screened by PCR and the virus mids were isolated from the bacteria and purified by a standard equilibrium centrifugation in CsCl-ethidium bromide gradient (22). Virus mids were transfected with the calcium-phosphate method in a packaging cell line (HER911 Tet) to get the recombinant adenovirus (Fø generation). The transfected cells were harvested, lysed by repeated freezing-thawing and centrifuged. The supernatant, containing 
the viral particles, was used to infect HER911 Tet cells for a larger scale preparation (F1 generation). The titer $\left(\mathrm{TCID}_{50}\right)$ of the F1 viral generation was finally determined with the Reed-Muench method (23).

\section{INFECTION OF MEFs}

Mouse embryonic fibroblasts were seeded in 96-wells plates ( 3000 cells/well) and infected with the Ad-Per2 at 600 or 60 m.o.i ( $100 \mu \mathrm{l}$ volume of infection, $48 \mathrm{~h}$ incubation). Expression of the PER2 protein in cells was confirmed by Western blotting. As a control, MEFs were infected with an adenovirus containing the green fluorescent protein (GFP) gene in order to follow infection by microscopic inspection and to check the effects of the adenovirus on cell viability. After incubation, cells were treated with $600 \mu \mathrm{M}$ paraquat and incubated for $24 \mathrm{~h}$ at $37^{\circ} \mathrm{C}-5 \% \mathrm{CO}_{2}$. Cell death was evaluated with the cytotoxicity test mentioned above (Promega). All the experiments were performed in duplicate with populations of wild type or Per $2^{B r d m 1}$ mutant cells composed of three different cell lines equally represented. Data were compared by one-way ANOVA and Bonferroni's post hoc test.

\section{CIRCADIAN PROFILE OF SENSITIVITY TO PARAQUAT}

Cells were grown in 20\% FCS to confluency and $100 \mathrm{nM}$ dexametasone was added for clock synchronization (24). Dexamethasone was carefully washed away after $15 \mathrm{~min}$ and replaced with fresh DMEM with 20\% FCS. Six, 12, 18, and $24 \mathrm{~h}$ after dexamethasone shock $600 \mu \mathrm{M}$ paraquat was added to the wells and after $24 \mathrm{~h}$ incubation the cytotoxicity was evaluated as described above.

\section{$\mathrm{H}_{2}$ DCFDA STAINING}

Cells were grown in 96-well plates to $80-90 \%$ confluency. After washes $25 \mu \mathrm{M} \mathrm{H}_{2}$ DCFDA ( $2^{\prime}, 7^{\prime}$-dichlorodihydrofluorescein diacetate) diluted in phenol-red free medium without FCS were added, and cells were incubated for $30 \mathrm{~min}$ at $37^{\circ} \mathrm{C}$. Subsequently, cells were washed once with PBS and fresh PBS was added. Fluorescence of DCF $\left(2^{\prime}, 7^{\prime}\right.$-dichlorofluorescein $)$ was measured at $485 \mathrm{~nm}$ excitation and $528 \mathrm{~nm}$ emission wavelength in a Synergy HT multi-mode plate reader (BioTek). Values for cells treated with phenol-red free medium alone were subtracted from all other values.

\section{MITOCHONDRIAL STAINING}

Wild type and Per $2^{B r d m 1}$ mutant MEFs were cultured in 8-well slide chambers at a density of $10^{4}$ cells/well. Culturing medium was replaced with fresh medium containing $100 \mathrm{nM}$ MitoTraker ${ }^{\circledR}$ Green FM (Molecular Probes, M7514). After 45 min at $37^{\circ} \mathrm{C}$, the medium was removed and the slides inspected under the microscope and photographed.

\section{SEMIQUANTITATIVE PCR}

PCR amplification of a $2.3 \mathrm{~kb}$ fragment of mitochondrial DNA (mtDNA) was performed by using the primers described in Ref. (25). The PCR was performed as follows: denaturation step of $3 \mathrm{~min}$ at $94^{\circ} \mathrm{C}$, then $15-35$ cycles of denaturation-annealingextension (denaturation $94^{\circ} \mathrm{C} 1 \mathrm{~min}$, annealing $55^{\circ} \mathrm{C} 2 \mathrm{~min}$, extension $72^{\circ} \mathrm{C} 2 \mathrm{~min}$ ). After a final extension step of $10 \mathrm{~min}$ at $72^{\circ} \mathrm{C}$, the tubes were chilled on ice and $8 \mu$ l of PCR products were loaded onto a $1 \%$ agarose gel.
For analysis of the circadian expression profile of Cry1 in synchronized cultures, cells were synchronized with dexamethasone as described above and samples were prepared $0,3,6,12,18$, and $24 \mathrm{~h}$ after synchronization. For the assessment of $b c l-2$ expression following paraquat treatment, cells were treated with paraquat for $24 \mathrm{~h}$. Total RNA was prepared using RNAzolB (WAK Chemie Steinbach, Germany; WAK-CS-1005) according to manufacturer's instructions. Contaminating genomic DNA was removed using DNA-free (Ambion, 1906) according to manufacturer's instructions followed by phenol:chloroform extraction. RNA integrity was checked on a $0.8 \%$ agarose gel and concentration was determined spectrophotometrically. Two micrograms of total RNA were reverse transcribed using SuperScriptII reverse transcriptase (Invitrogen, 18064-014).

For amplification of histone $2 \mathrm{Az}, \mathrm{bcl}-2$, and $\mathrm{Cr} y 1$, the following primers were used:

\section{$H 2 A z$ forward $5^{\prime}$-CGTATTCATCGACACCTGAAA-3' $H 2 A z$ reverse $5^{\prime}$-CTGTTGTCCTTTCTTCCCGAT-3' $b c l-2$ forward $5^{\prime}$-CCCCACCGAACTCAAAGAAG- $3^{\prime}$ $b c l$-2 reverse $5^{\prime}$-CGGGAGAACAGGGTATGATA-3' Cry 1 forward 5'-CCTGGACAAGATCATAGAACTCA-3' Cry 1 reverse 5'-CCAAAGCGGAGATAAGGACTGAG-3'}

PCR conditions were $30 \mathrm{~s}$ denaturation at $94^{\circ} \mathrm{C}$, $30 \mathrm{~s}$ primer annealing $\left(\mathrm{H} 2 \mathrm{Az}\right.$ : $\left.50^{\circ} \mathrm{C}, \mathrm{bcl}-2: 56^{\circ} \mathrm{C}, \mathrm{Cry} 1: 54^{\circ} \mathrm{C}\right)$, and $1 \mathrm{~min}$ elongation for 30-37 cycles. PCR products were run on 1.5\% agarose gels, bands were quantified (QuantityOne 3.0, Biorad), and $b c l-2$ and $C r y 1$ expression was normalized to $H 2 A z$. Subsequently, the data were analyzed by a $t$-test.

\section{ANNEXIN V AND PROPIDIUM IODIDE STAINING}

Annexin $\mathrm{V}$ and propidium iodide staining were performed using a BD Biosciences kit (no. 550911 and 556463). Cells were plated in an eight chambered slide $\left(5-10 \times 10^{3}\right.$ cells/well $)$ and treated with $600 \mu \mathrm{M}$ paraquat. Ten and $16 \mathrm{~h}$ after the beginning of the treatment the medium was removed and cells were washed once with PBS and annexin V binding buffer $(250 \mu \mathrm{l} /$ well $)$. Cells were then incubated with annexinV-FITC antibody (diluted 1:10 in annexin $\mathrm{V}$ binding buffer, $250 \mu \mathrm{l} /$ well) and propidium iodide $(0.5 \mu \mathrm{g} / 250 \mu \mathrm{l})$ at $37^{\circ} \mathrm{C}$ in darkness for $30 \mathrm{~min}$.

\section{GEArray}

Apoptosis GEArray Q series membranes (SuperArray Biosciences, Bethesda, MD, USA, No. MM-002) were hybridized with labeled cDNA obtained from mRNA extracted from MEFs of the two genotypes according to the manufacturer's instructions. The dried array membranes were then scanned using an Odyssey infrared imaging system (LI-COR Biosciences). Images were analyzed using the web-based GEArray expression analysis suite (Super Array Biosciences, Bethesda, MD, USA).

\section{WESTERN BLOTS}

Proteins were separated by SDS-PAGE and transferred onto nitrocellulose membranes. Membranes were incubated with antiPER2 antibody (Beckton-Dickinson, GP81620-050) 1:1000, antip53 antibody (Oncogene, OP03) 1:1000, or anti-actin antibody 
(Sigma, A5060) 1:1000 (all diluted in blocking buffer) at $4^{\circ} \mathrm{C}$ over night. They were washed and subsequently incubated with appropriate HRP-conjugated secondary antibodies (anti-rabbit for actin, anti-mouse for PER2 and p53; both Sigma, A9169 and A9044) for $1 \mathrm{~h}$ at RT. Detection was performed using the Western blotting detection reagents kit (Amersham Biosciences, 1059243) according to manufacturer's instructions. Membranes were exposed on Hyperfilm (Amersham Biosciences, RPN1678K). For quantitative analysis, bands were quantified (QuantityOne 3.0, Biorad), and band intensity was normalized to actin.

\section{RESULTS}

\section{ELEVATED RESISTANCE OF Per2 ${ }^{\text {Brdm1 }}$ MUTANT CELLS TO OXIDATIVE STRESS}

To evaluate the relationship between Per 2 and the cellular response to oxidative stress, we treated MEFs with paraquat, a chemical that increases ROS production inside the cell by interfering with the oxidative chain by reducing oxygen to oxygen radicals. Comparison between wild type and $P e r 2^{B r d m 1}$ mutant MEFs revealed a sigmoidal dose response curve to paraquat and a better survival rate for $P e r 2^{B r d m 1}$ mutant cells after $400-800 \mu \mathrm{M}$ paraquat treatment (Figure 1A). Application of NAC, a radical scavenger, abolished the cytotoxic effect of paraquat on the cells, indicating that the observed cytotoxicity is due to radicals (Figure 1B). Other ROS generating agents such as UV, plumbagin (26), and SIN-1 treatment confirmed the elevated resistance of Per $2^{\text {Brdm } 1}$ mutant cells to oxidative stress (Figures 1C-E). Therefore, we suspected that Per2 plays a role in the regulation of cellular responses to oxidative stress.

\section{RESCUE OF Per2 MUTANT MEFs}

Expression of Per2 in Per2 $2^{B r d m 1}$ mutant cells should rescue the observed phenotype and make these MEFs more susceptible to oxidative stress, comparable to wild-type cells. We introduced the wild-type Per 2 gene into Per $2^{B r d m 1}$ mutant MEFs using an adenovirus to express the PER2 protein under the cytomegalovirus (CMV) promoter in those cells (Ad-Per2) (see Figure S1 in Supplementary Material). As a control, the same viral vector expressing GFP was used $(A d-G F P)$. After $48 \mathrm{~h}$, we treated the cells with $600 \mu \mathrm{M}$ paraquat and measured cell death $24 \mathrm{~h}$ thereafter. At a multiplicity of infection (moi) of 600 Ad-Per 2 restored paraquat induced cytotoxicity in Per $2^{\mathrm{Brdm} 1}$ mutant cells from $37.7 \pm 2(\%$ cytotoxicity \pm SEM) to $45.5 \pm 3.1 \%$, a level comparable to wildtype cells $(43.9 \pm 1.3 \%)$ (Table 1). The same amount of Ad-GFP had no effect ( $35.2 \pm 4.4 \%)$. Expression of Ad-Per2 and Ad-GFP in wild-type cells did not alter their response to paraquat significantly $(46.6 \pm 1.2$ and $44.5 \pm 1.6 \%$, respectively, Table 1$)$. These results indicate a causal relationship between Per 2 and the modulation of cell death in response to oxidative stress.

\section{TIME DEPENDENCE IN PARAQUAT SENSITIVITY AND OXIDATIVE STATE}

As a next step, we addressed the question whether the sensitivity of the cells to paraquat is of circadian nature. Therefore, we synchronized the circadian clocks in MEFs using dexamethasone as described previously (24) and monitored expression of the clock gene Cry 1 to confirm synchronization of the cellular clocks (Figure 2A, bottom panel). After dexamethasone application and subsequent $24 \mathrm{~h}$ paraquat treatment maximal cytotoxicity is observed in wild type and Per $2^{\mathrm{Brdm} 1}$ mutant MEFs 3 and $24 \mathrm{~h}$ after clock synchronization. However, at times in between $(6,12$, and $18 \mathrm{~h})$ cytotoxicity is decreased $(p<0.0001)$ (Figure 2A). Consistent with the finding in non-clock-synchronized cells (Figure 1A), significant differences in sensitivity to paraquat between wild type and $\operatorname{Per} 2^{\mathrm{Brdm1}}$ mutant MEFs can be observed (Figure 2A, $6 \mathrm{~h}$ after dexamethasone: wild type: $30.3 \pm 1 \%$, Per $2^{B r d m 1}$ : $25.9 \pm 0.9 \%$; cytotoxicity in $\% \pm \mathrm{SEM}, p<0.05$, and $12 \mathrm{~h}$ after dexamethasone: wild type: $32.5 \pm 1.2 \%$, Per2 $2^{B r d m 1}$ : $26.5 \pm 1.3 \%$; cytotoxicity in $\% \pm$ SEM, $p<0.01)$. It appears that clock synchronized MEFs cultured in $20 \%$ serum are in general more resistant to paraquat compared to asynchronous cells grown in presence of $10 \%$ serum. The reason for this difference is that serum contains radical scavengers and hence cultures with higher serum content have a higher capacity to buffer ROS. Introduction of the wild-type Per2 gene into Per $2^{B r d m 1}$ mutant MEFs $6 \mathrm{~h}$ after dexamethasone treatment results in an increase of sensitivity to the cytotoxic effects of paraquat and reaches a level observed in wild-type MEFs (Figure 2B, wild type: $28.1 \pm 1 \%, \operatorname{Per} 2^{\mathrm{Brdm} 1}$ : $22.5 \pm 1.3 \%$, wild type + Ad-Per $2: 27.6 \pm 0.5 \%, \operatorname{Per} 2^{\text {Brdm1 }}+$ AdPer2: $27.4 \pm 0.6 \%$; cytotoxicity in $\% \pm$ SEM, $p<0.05)$. This is accompanied by an alteration in the oxidative state (Figure 2C). We find that the $\mathrm{NADH} / \mathrm{NAD}^{+}$ratio is significantly higher in clock synchronized Per $2^{\mathrm{Brdm} 1}$ mutant cells compared to wild type (wild type: $0.14 \pm 0.02, P e r 2^{B r d m 1}: 0.33 \pm 0.06, \mathrm{NADH}^{\mathrm{N}} \mathrm{NAD}^{+} \pm \mathrm{SEM}$, $p<0.05)$. This ratio can be normalized to wild-type levels when the complete Per2 gene is introduced via adenovirus into Per $2^{\text {Brdm1 }}$ mutant MEFs $(0.1 \pm 0.04)$, but not when GFP is introduced $(0.41 \pm 0.03$, Figure 2C). Over expressing the Per2 gene in Per $2^{B r d m 1}$ mutant MEFs probably has a strong influence on the cellular clock. Therefore, it is not clear whether the rescue of oxidative state is a direct consequence of Per2 or whether other clock components such as cryptochromes are the mediators of this process. These results, however, indicate that Per2 is involved in regulating the oxidative state of a cell and influences the cellular response to oxidative stress in a direct or indirect manner.

\section{ENDOGENOUS ROS, SENSITIVITY TO PEROXIDE AND MITOCHONDRIAL FUNCTION}

To find whether the Per2 gene influences the endogenous amount of ROS in a cell, we evaluated the endogenous amount of ROS present in wild type and Per $2^{B r d m 1}$ mutant MEFs via aconitase activity, an enzyme of the Krebs cycle that is sensitive to ROS (14). Aconitase activity in both wild type and Per2 $2^{B r d m 1}$ MEFs is comparable and suggests the presence of similar amounts of endogenous ROS in both genotypes (Figure 3A). Because ROS, particularly superoxide anions, can be eliminated in a cell by SOD (27), we measured the amount of total SOD activity (cytoplasmic and mitochondrial) in both genotypes. No differences were observed (Figure 3A), which is consistent with the aconitase assay. There were also no significant differences between the two genotypes in the activity of the control enzyme lactate dehydrogenase (LDH) (Figure 3A). Additionally, LDH did not show a circadian activity pattern in wild type and $P e r 2^{B r d m 1}$ mutant brain tissue (see Figure S2 in Supplementary Material). These observations indicate that the levels of total endogenous ROS in wild type 


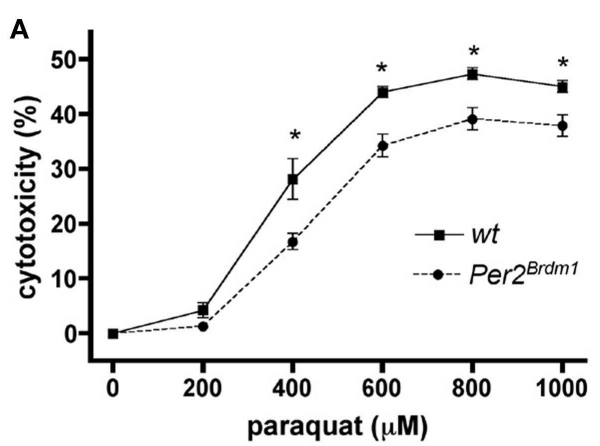

B

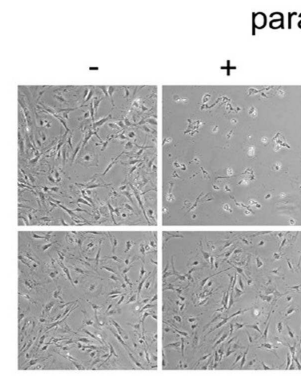

$w t$ paraquat

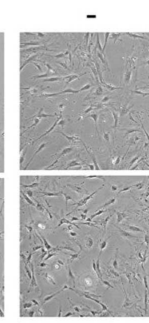

Per2 ${ }^{\text {Brdm1 }}$

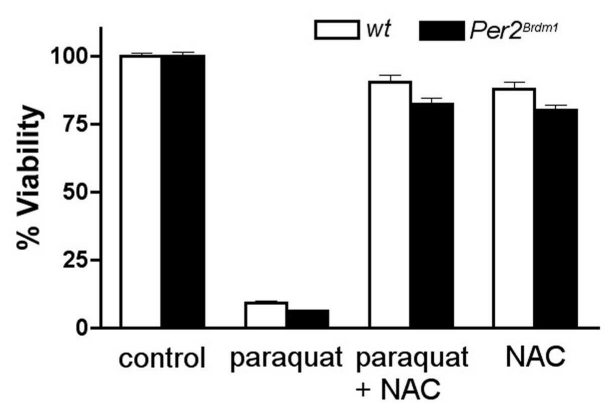

medium

medium

$+$

NAC

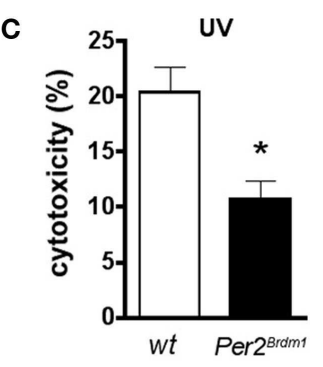

D

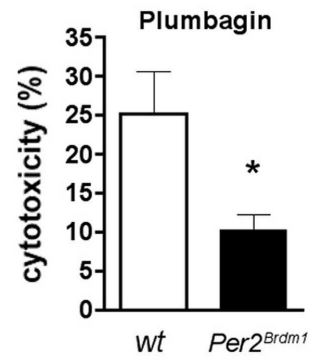

SIN-1

E

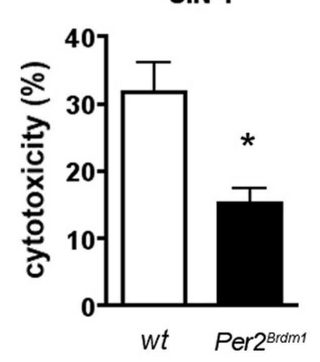

FIGURE 1 | Mutation in the clock gene Per2 leads to altered response of asynchronous cells to oxidative stress. (A) Mouse embryonic fibroblasts (MEFs) of wild type ( $w t$, solid line) and Per2 mutant mice (Per2 ${ }^{\text {Brdm } 1}$, hatched line) display differences in cytotoxicity in response to various amounts of paraquat. LDH released into the medium versus LDH in living cells was measured after $24 \mathrm{~h}$ of paraquat treatment to determine cytotoxicity $(n=4-5$ MEF preparations per genotype, ${ }^{*} p<0.05$ two-way-ANOVA with subsequent Bonferroni test). Cell death due to plating was deducted ( $w t=7 \pm 0.8 \%$,
Per2 ${ }^{\text {Brdm1 }}=7.4 \pm 1 \%, n=3$ ) (B) $N$-acetyl cystein (NAC), a radical scavenger, reverses paraquat mediated cytotoxicity. About $100 \mathrm{mM}$ NAC was added to MEFs and subsequently the cells were treated with $600 \mu \mathrm{M}$ paraquat. Top: photomicrographs of cells. Scale bar $=200 \mu \mathrm{m}$. Bottom: quantification of viability using the crystal violet method. (C) Wild type (wt, white bar) and Per2 mutant (Per2 ${ }^{\text {Brdm }}$, black bar) MEFs display differences in cytotoxicity in response to ultra-violet (UV) treatment $\left(120 \mathrm{~mJ} / \mathrm{cm}^{2}\right)$, in response to plumbagin $(1.5 \mu \mathrm{M})$ (D), and in response to SIN-1 (2 mM) (E) $\left(^{*} p<0.05\right)$. and $\operatorname{Per} 2^{B r d m 1}$ mutant MEFs are not significantly different under unstressed conditions. However, sub-cellular differences in ROS production cannot be excluded.

To decipher whether the higher resistance of $\mathrm{Per} 2^{\mathrm{Brdm} 1}$ mutant MEFs toward oxidative stress was due to the intracellular defense system or to a higher strength of cell membranes toward lipid peroxidation, hydrogen peroxide $\left(\mathrm{H}_{2} \mathrm{O}_{2}\right)$ was applied to the cells. Exposure to high $\mathrm{H}_{2} \mathrm{O}_{2}$ concentrations for long periods induces necrotic rather than apoptotic cell death by direct damage of cell membranes (28). After $24 \mathrm{~h}$ exposure to $\mathrm{H}_{2} \mathrm{O}_{2}$ at different concentrations no significant difference between $\mathrm{Per} 2^{\mathrm{Brdm} 1}$ mutant and wild-type MEFs could be observed (Figure 3B) indicating that the resistance of $\mathrm{Per} 2^{\mathrm{Brdm} 1}$ mutant cells toward paraquat, plumbagin, SIN-1, and UV treatment is not the result of ROS scavenging processes at the cell membrane. Therefore, we tested enzymatic activities in mitochondria that contribute to radical production. We measured the activity of complex I (NADH ubiquinone oxidoreductase) of the oxidative chain in the mitochondria, which transports electrons from $\mathrm{NADH}$ to ubiquinone and thereby influences the oxidative state of a cell (Figure 3C). We find that its activity under saturating conditions is significantly lower in $\mathrm{Per} 2^{\mathrm{Brdm} 1}$ mutant cells (wild type: $144.4 \pm 4.5 \mathrm{nmol} / \mathrm{min} / \mathrm{mg}, P e r 2^{B r d m 1}$ 
Table 1 | Per2 influences sensitivity to reactive oxygen species (ROS)

\section{Conditions}

\begin{tabular}{ccccccc}
\hline Vehicle & Paraquat & Ad-Per2 & Ad-GFP & & wt & Per2 $^{\text {Brdm1 }}$ \\
\hline+ & - & - & - & $0.2 \pm 0.6$ & $0 \pm 1.0$ \\
+ & + & - & - & $43.9 \pm 1.3$ & $37.7 \pm 2.0^{*}$ \\
- & - & + & - & $4.3 \pm 1.3$ & $4.4 \pm 0.6$ \\
- & - & - & + & $1.4 \pm 0.4$ & $0.1 \pm 0.9$ \\
+ & + & + & - & $46.6 \pm 1.2$ & $45.5 \pm 3.1$ \\
+ & + & - & + & $44.5 \pm 1.6$ & $35.2 \pm 4.4^{*}$
\end{tabular}

MEFs were treated with $600 \mu \mathrm{m}$ paraquat and infected with 600 moi (moi, multiplicity of infection) of adenovirus containing either the wild-type Per2 gene (Ad-Per2) or green fluorescent protein (Ad-GFP). After $24 \mathrm{~h}$, the supernatants of the cultures were assayed for LDH enzyme activity. Cytotoxicity was determined by the ratio of released $L D H$ over maximal $L D H$. Cell death due to plating was deducted ( $w t=7.8 \pm 0.4 \%$, Per $2^{\text {Brdm } 1}=7.8 \pm 0.5 \%, n=3$ ). The data are presented as mean $\pm S E M$ of three experiments. ${ }^{*} p<0.05$. mutant: $113.1 \pm 4.6 \mathrm{nmol} / \mathrm{min} / \mathrm{mg}, p=0.0012)$ indicating that production of oxygen radicals through interference of paraquat with complex I is reduced. In order to test this conjecture, we determined intracellular ROS levels after paraquat treatment using $\mathrm{H}_{2}$ DCFDA $\left(2^{\prime}, 7^{\prime}\right.$-dichlorodihydrofluorescein diacetate), which is oxidized by ROS [especially $\mathrm{H}_{2} \mathrm{O}_{2}$ (29)] to the highly fluorescent DCF $\left(2^{\prime}, 7^{\prime}\right.$-dichlorofluorescein) (30). As hypothesized, the changes in intracellular ROS after $6 \mathrm{~h}$ of paraquat treatment were minimal in Per $2^{\mathrm{Brdm} 1}$ mutant MEFs, whereas a clear increase was observed in wild-type MEFs (Figure 3D). No changes were seen at basal levels, which is in line with the observation in Figure 1B. These results indicate that the lower sensitivity of Per $2^{B r d m 1}$ mutant MEFs to paraquat is not due to altered basal ROS levels, but to a decrease in ROS production in response to paraquat exposure.

\section{AMOUNT OF MITOCHONDRIA AND bcl-2 EXPRESSION}

Changes in oxidative state have been described for cells depleted of mtDNA (25). Therefore, we tested whether Per $2^{\text {Brdm } 1}$ mutant MEFs contain less mitochondria (Figure 4A). Staining with

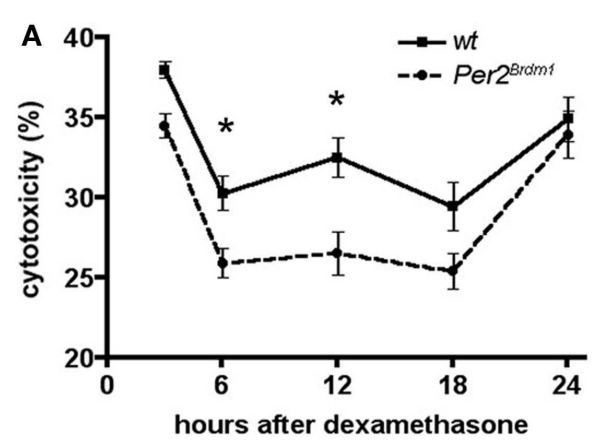

hours $\begin{array}{lllllllllll} & 3 & 6 & 1218 & 24 & \mathrm{c} & 0 & 3 & 6 & 121824\end{array}$
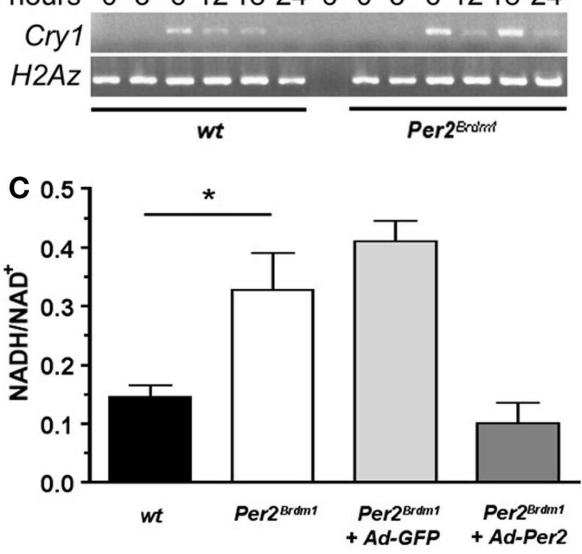

FIGURE 2 |Time dependent sensitivity of synchronized wild type and Per2 $^{\text {Brdm } 1}$ mutant MEFs to paraquat and altered oxidative state in Per2 ${ }^{\text {Brdm } 1}$ mutant MEFs. (A) Cells were synchronized with dexamethasone and treated with paraquat after the indicated times. $\mathrm{LDH}$ released into the medium versus $\mathrm{LDH}$ in living cells was measured after $24 \mathrm{~h}$ of paraquat treatment to determine cytotoxicity. Cytotoxicity of paraquat in both genotypes is time dependent and significantly reduced in $\operatorname{Per} 2^{B \text { rdm }}{ }^{2}$ mutant MEFs $\left({ }^{*} p<0.05\right.$, $n=3$ ). The panel below shows clock synchronization of MEFs monitored by expression of $\mathrm{Cry} 1$ relative to the histone $\mathrm{H} 2 \mathrm{Az}$. Wild-type cells show a

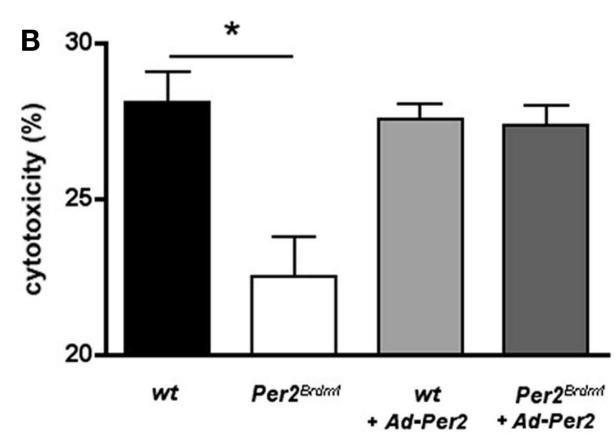

significant 24 h cycling ( ${ }^{*} p<0.05, n=3$ ) whereas Per2 ${ }^{\text {Brdm1 }}$ mutant MEFs display altered Cry1 expression. Significant differences in Cry1 expression in these cells at 6 and $18 \mathrm{~h}$ are observed $\left({ }^{*} p<0.05, n=3\right)$. (B) Rescue of sensitivity toward paraquat in Per2 ${ }^{\text {Brdm1 }}$ mutant MEFs $6 \mathrm{~h}$ after dexamethasone treatment by introduction of the wild-type Per2 gene into Per2 ${ }^{\text {Brdm } 1}$ mutant MEFs using adenovirus (Ad-Per2) $\left({ }^{*} p<0.05, n=3\right.$ ). (C) $\mathrm{NADH} / \mathrm{NAD}^{+}$ratio is elevated in Per2 ${ }^{\text {Brdm } 1}$ mutant MEFs $\left({ }^{*} p<0.05, n=3\right)$. This ratio is normalized to wild-type levels by introduction of the wild-type Per2 gene (Ad-Per2) but not GFP (Ad-GFP) using adenovirus $(n=3)$. 


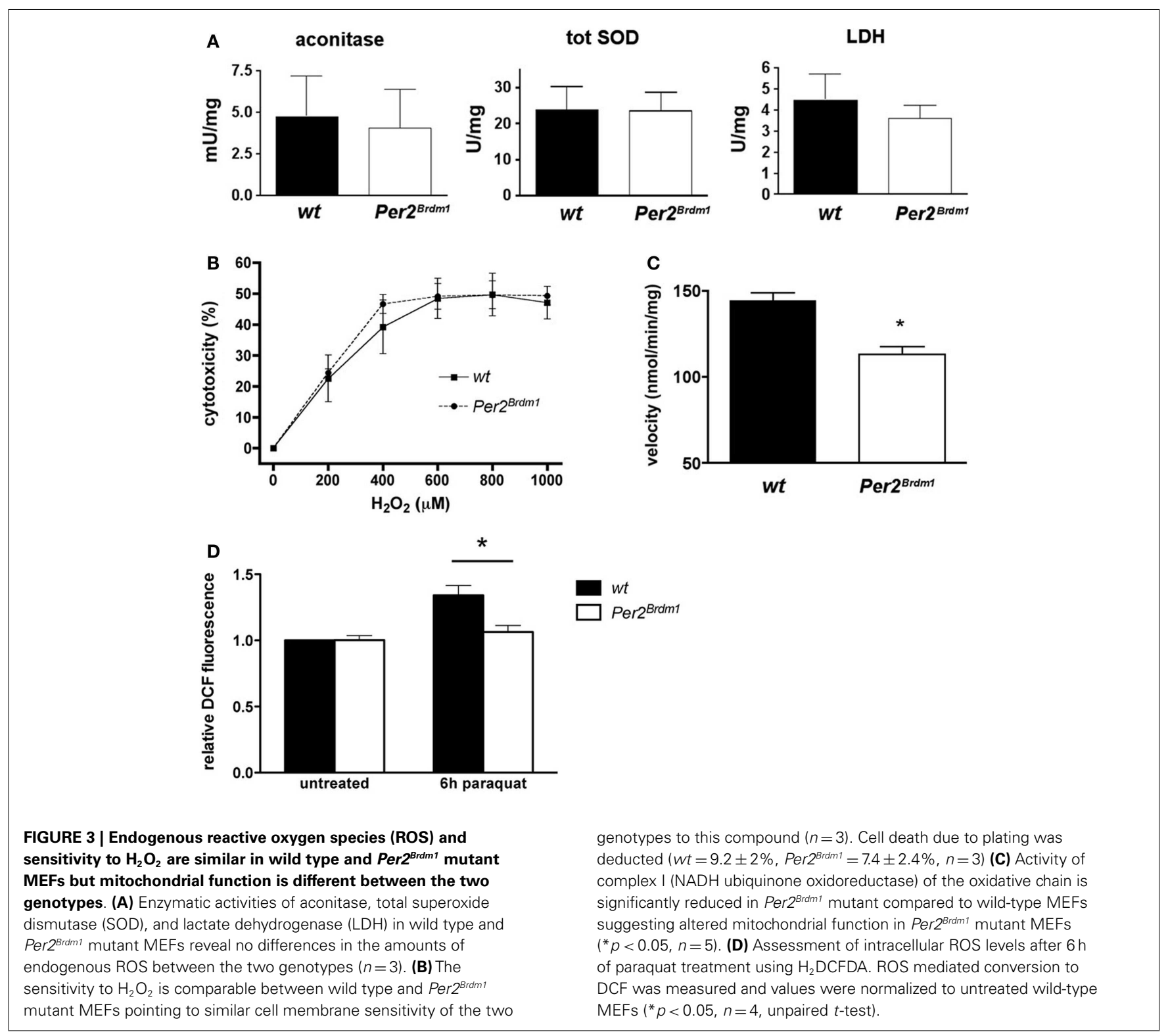

MitoTraker ${ }^{\circledR}$ Green, a dye specifically labeling mitochondria regardless of mitochondrial membrane potential, did not reveal gross differences between wild type and Per $2^{B r d m 1}$ mutant cells. In addition, semiquantitative PCR did not uncover differences in mtDNA contents relative to nuclear DNA (Figure 4B). Therefore, we conclude that our findings are not due to less mitochondria in Per $2^{B r d m 1}$ mutant MEFs. It appears that the described observations are the consequence of transcriptional and/or posttranscriptional events regulated by the Per2 gene. To evaluate whether the MEFs used in the described experiments undergo apoptosis, we took advantage of the fact that apoptotic cells lose plasma membrane asymmetry. We measured the presence of phosphatidylserine (PS), an aminophospholipid that is normally present in the inner leaflet of the plasma membrane, but translocates in early apoptosis to the outer leaflet of the membrane. We measured this process via annexin, a protein with high affinity for PS to indirectly monitor PS translocation. We find that staining for annexin $\mathrm{V}$ is already seen $10 \mathrm{~h}$ after paraquat treatment (Figure 4C, green color) and only in a few cells DNA was visualized by propidium iodide (Figure 4C, orange color). This indicates that $10 \mathrm{~h}$ after paraquat treatment cells are in early apoptosis and the cell membranes are still intact preventing penetration of propidium iodide into the cells. Sixteen hours after paraquat treatment labeled DNA is observed in most cells (Figure 4C, orange color) indicating that cell membranes are damaged typical for late apoptosis. In the cytotoxicity experiments described above assessment was made $24 \mathrm{~h}$ after paraquat treatment and hence our evaluation includes cells with defective membranes. To obtain a quantifiable measure for apoptosis, we investigated the expression levels of $b c l-2$, a well-characterized regulator of apoptosis (31). Using an apoptosis pathway cDNAarray, we found that expression of the anti-apoptotic gene $b c l-2$ is increased in $\operatorname{Per} 2^{\mathrm{Brdm} 1}$ mutant cells compared to wild-type 
A
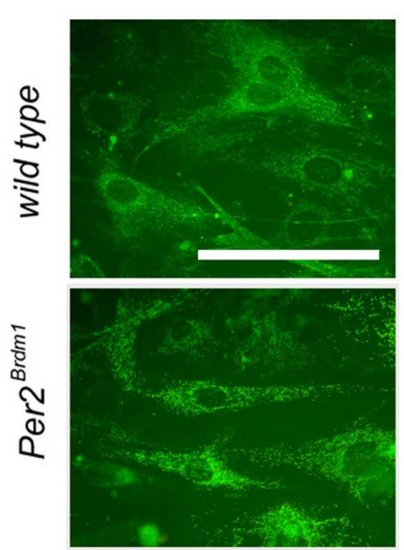

B
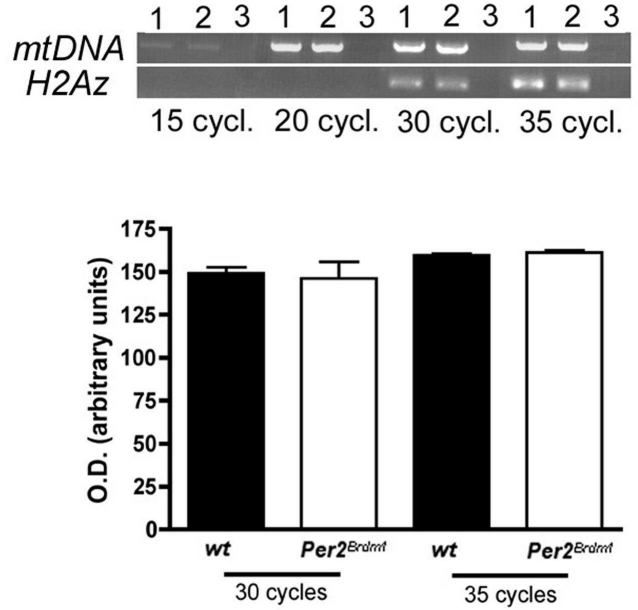

C

$10 \mathrm{~h}$
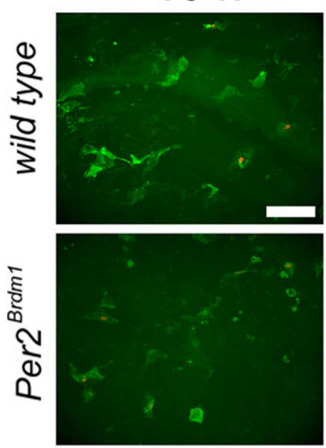

$16 \mathrm{~h}$
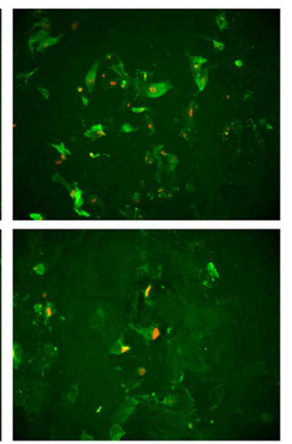

D

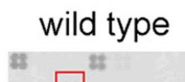

bc/2
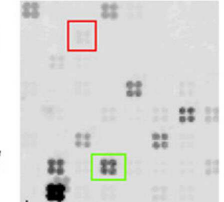

$$
\text { fadd }
$$

Per2 ${ }^{\text {Brdm1 }}$

国

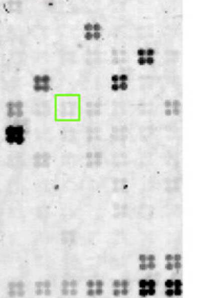

controls

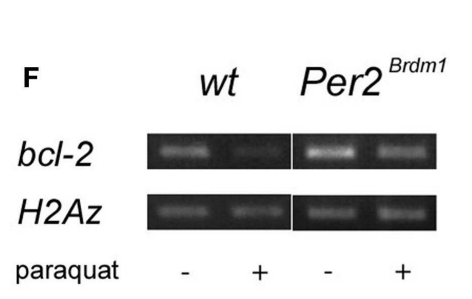

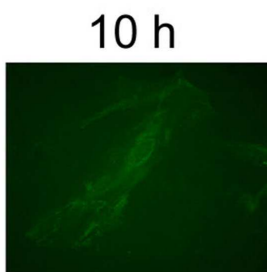
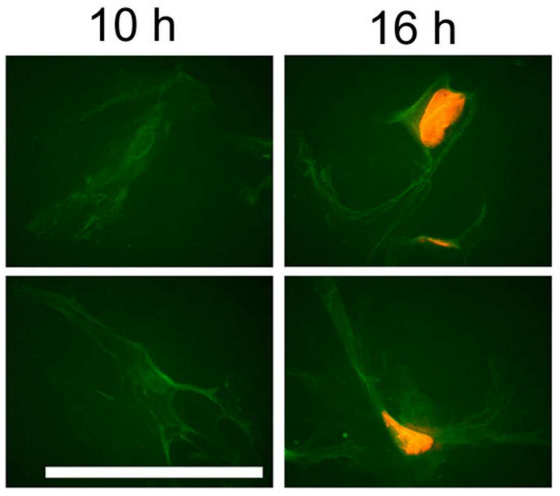

E
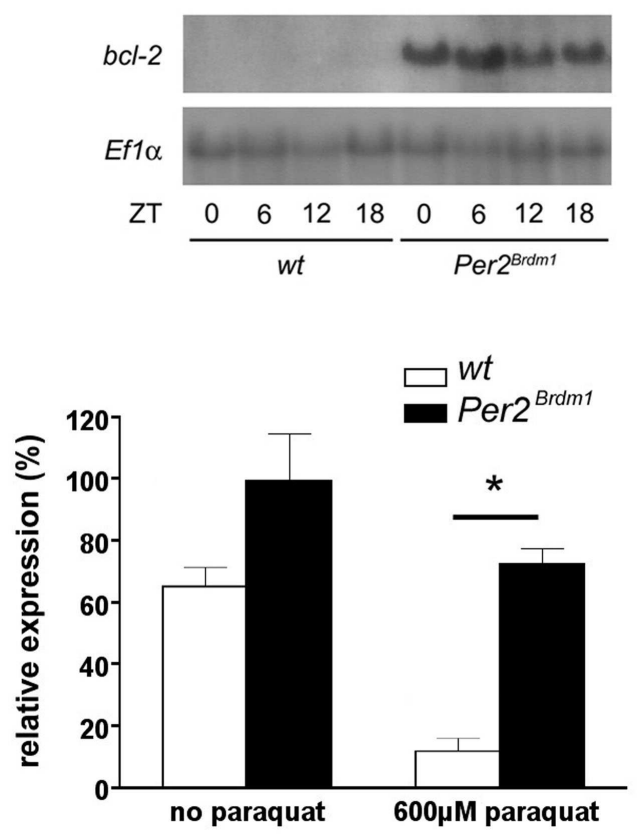

FIGURE 4 | Amount of mitochondrial DNA in MEFs, apoptosis after paraquat treatment and bcl-2 expression. 


\section{FIGURE 4 | Continued}

(A) Labeling of mitochondria with MitoTraker®Green FM. No difference in number of mitochondria can be detected between wild type and Per2 ${ }^{\text {Brdm } 1}$ mutant MEFs (scale bar $=100 \mu \mathrm{m}$ ). (B) Top panel: PCR amplification of a $2.3 \mathrm{~kb}$ fragment of mitochondrial DNA ( $m$ tDNA) is compared to amplification of a $0.3 \mathrm{~kb}$ fragment of nuclear DNA (histone $\mathrm{H} 2 \mathrm{Az}$ ) after 15, 20, 30, and 35 cycles. Lane $1=$ wild type, lane $2=$ Per ${ }^{\text {Brdm } 1}$ mutant, lane $3=$ no DNA. Similar amounts of mtDNA relative to histone $\mathrm{H} 2 \mathrm{Az}$ DNA are observed in both genotypes. Bottom panel: quantification of amplified mtDNA normalized to histone H2Az DNA after 30 and 35 cycles $(n=3)$. (C) Staining of wild type and Per2 ${ }^{\text {Brdm } 1}$ mutant MEFs with annexin $\mathrm{V}$ (green) and propidium iodide (orange)
10 and $16 \mathrm{~h}$ after paraquat treatment at low (left panel) and high (right panel) magnification. Scale bar $=100 \mu \mathrm{m}$. (D) Example of apoptosis GEArrays after hybridization with labeled cDNA probes of untreated wild-type and Per2 $2^{\text {Brdm } 1}$ mutant MEFs. Three arrays per genotype were hybridized and genes significantly changed in expression are marked by colored squares, bcl-2 (red) and fadd (green). Controls (two bottom rows) were PUC18 plasmid, blank spots (non-specific binding), Ppia and Rp/13a as positive controls and two housekeeping genes for normalization (b-actin and Gapdh). (E) Northern blot of mRNA isolated from livers of wild-type and Per2 ${ }^{\text {Brdm1 }}$ mutant mice sacrificed at the indicated time points. (F) Expression of $b c /-2$ in wild type and Per2 ${ }^{\text {Brdm } 1}$ mutant MEFs before and after paraquat treatment $\left(n=3,{ }^{*} p<0.05\right)$.
(Figure 4D) and were able to confirm this observation in liver tissue (Figure 4E). Interestingly, the pro-apoptotic gene fadd was down-regulated in Per $2^{B r d m 1}$ mutant cells (Figure 4D). After paraquat treatment, there is a significantly stronger decrease in the expression of $b c l-2$ in wild-type cells as compared to Per $2^{B r d m 1}$ mutant cells (Figure 4F). Overall, these data suggest that apoptotic signaling pathways are different between wild-type and Per $2^{\text {Brdm1 }}$ mutants supporting our observation that Per2 modulates cell death in response to oxidative stress.

\section{DISCUSSION}

The present report provides evidence that the Per 2 gene plays a role in the cellular response to oxidative stress and cell death. This might be achieved through the regulatory potential of the Per2 gene on the redox state of a cell. The redox state of a cell has been proposed to be crucial for the regulation of clock gene dependent transcription via the NAD dependent enzyme SIRT1 $(32,33)$. Additionally, NAD modulates the DNA binding factors Clock and NPAS2 and their transcription potential (34). NADH favors formation of heterodimers between CLOCK or NPAS2 with BMAL1, which then bind to DNA at E-box promoter elements, thus regulating the efficiency with which many circadian clock and clock controlled genes are transcribed. Therefore, one would expect that the elevated amount of NADH in Per2 $2^{\text {Brdm1 }}$ mutant MEFs would favor the formation of heterodimeric CLOCK/BMAL1 or NPAS2/BMAL1 complexes and lead to an elevated transcription of target genes such as cryptochromes. This might partially compensate for the reduction in expression of Npas 2 and Bmal1 in Per $2^{B r d m 1}$ mutant cells and explain why Per $2^{B r d m 1}$ mutant mice can display circadian behavior for several days in constant darkness before they lose a circadian activity rhythm $(9,35)$. This view is compatible with the suggestion that redox regulation is part of the clock mechanism $(36,37)$. In this model, redox state does not only influence clock protein heterodimerization and thus might contribute to the transcriptional efficiency but redox state might also be regulated by clock components for which evidence is presented in this study. Hence, a feedback loop on redox state might involve the circadian clock (37). It makes sense that the clock and the redox state are interlaced since environmental oxidative stress on a cell has a diurnal pattern (38). Cells of an organism have evolved to meet time dependent oxidative stress and probably use the circadian clock for this purpose (see Figure 2A) (39). A mutation in a clock component, as shown here for Per2, will therefore alter the cellular response to oxidative stress in mammalian cells. A change in redox state as manifested by elevated levels of NADH might increase the radical scavenging properties of a cell (40), which leads to better survival in response to oxidative stress. This puts an increased pressure on the DNA repair mechanism to avoid accumulation of mutations. Interestingly, however, p53 protein is reduced in its expression in Per $2^{B r d m 1}$ mutant MEFs [Figure S3 in Supplementary Material, see also Ref. (10)]. This is probably due to the reduced activity of $\mathrm{NADH}$ ubiquinone oxidoreductase (Figure 3C), which has been implicated in the regulation of p53 stability and p53-dependent apoptosis (41). Additionally, Per2 $2^{B r d m 1}$ mutant MEFs do not reduce expression of the antiapoptotic gene $b c l-2$ as strong as wild-type cells in response to the ROS inducing agent paraquat. Therefore, $P e r 2^{B r d m 1}$ mutant MEFs undergo less apoptosis and survive better under oxidative stress in vitro. However, if DNA damage occurs it will lead to tumor formation in an organism in vivo as described previously $(10,42)$. This indicates that the Per 2 gene is not only involved in regulating redox state and response to oxidative stress in a cell but also affects apoptosis via p53 regulation. Per2 was identified as a component of the p53 pathway in a large-scale RNAi screen in human cells (43) indicating that the relationship between Per2 and p53 is bidirectional (44). Our results based on lack of Per2 are in agreement with the observation that overexpression of Per2 in various carcinoma cell lines reduced cellular proliferation with up-regulation of p53 and increased apoptosis that was accompanied by down-regulation of $b c l-2$ (45-47). Conversely, flutamide, an anti-prostate cancer drug and apoptosis inducer, up-regulated Per2 gene expression in prostate mesenchymal cells (48). Interestingly, two cytotoxicity response regulators Ly49C and $N k g 2 d$ are down-regulated in Per $2^{\mathrm{Brdm} 1}$ mutant mice (49) supporting a role of Per2 in the regulation of cytotoxicity responses.

The above discussion illustrates that although a mutation in the Per2 gene makes cells more resistant to oxidative stress, $\operatorname{Per} 2^{\mathrm{Brdm} 1}$ mutant cells contribute to cancer formation in the organism (10). Hence, the Per2 gene seems to enhance biological fitness by establishing an optimal balance between cell survival and programed cell death. This does not necessarily lead to maximal longevity under ideal circumstances but optimizes survival of an organism in real life experiencing a variety of different types of environmental stress. In sum, this report provides evidence that the circadian clock gene Per 2 influences cellular response to oxidative stress and modulates cell death, which in turn affects cancer development and the aging process.

\section{ACKNOWLEDGMENTS}

We thank Gurudutt Pendyala, James Delorme, and Drs. Zihong Yang and Jürgen Ripperger for suggestions on the manuscript. 
This work was supported by SNF grant 3100AO-104222/1, EC grant Braintime QLG3-CT-2002-01829, and the BBW (Urs Albrecht), the AETAS Foundation, and the Hans Wilsdorf Foundation (Sandro Rusconi and Urs Albrecht) and the State of Fribourg.

\section{SUPPLEMENTARY MATERIAL}

The Supplementary Material for this article can be found online at http://www.frontiersin.org/Journal/10.3389/fneur.2014.00289/ abstract

\section{REFERENCES}

1. Aschoff J. Circadian timing. Ann N Y Acad Sci (1984) 423:442-68. doi:10.1111/ j.1749-6632.1984.tb23452.x

2. Pittendrigh CS. Temporal organization: reflections of a Darwinian clockwatcher. Annu Rev Physiol (1993) 55:16-54. doi:10.1146/annurev.ph.55.030193. 000313

3. Hastings $\mathrm{MH}$, Reddy AB, Maywood ES. A clockwork web: circadian timing in brain and periphery, in health and disease. Nat Rev Neurosci (2003) 4:649-61. doi:10.1038/nrn1177

4. Balsalobre A, Damiola F, Schibler U. A serum shock induces circadian gene expression in mammalian tissue culture cells. Cell (1998) 93:929-37. doi:10. 1016/S0092-8674(00)81199-X

5. Reppert SM, Weaver DR. Coordination of circadian timing in mammals. Nature (2002) 418:935-41. doi:10.1038/nature00965

6. Preitner N, Damiola F, Lopez-Molina L, Zakany J, Duboule D, Albrecht U, et al. The orphan nuclear receptor REV-ERBalpha controls circadian transcription within the positive limb of the mammalian circadian oscillator. Cell (2002) 110:251-60. doi:10.1016/S0092-8674(02)00825-5

7. Claridge-Chang A, Wijnen H, Naef F, Boothroyd C, Rajewsky N, Young MW. Circadian regulation of gene expression systems in the Drosophila head. Neuron (2001) 32:657-71. doi:10.1016/S0896-6273(01)00515-3

8. Panda S, Antoch MP, Miller BH, Su AI, Schook AB, Straume M, et al. Coordinated transcription of key pathways in the mouse by the circadian clock. Cell (2002) 109:307-20. doi:10.1016/S0092-8674(02)00722-5

9. Zheng B, Larkin DW, Albrecht U, Sun ZS, Sage M, Eichele G, et al. The mPer2 gene encodes a functional component of the mammalian circadian clock. Nature (1999) 400:169-73. doi:10.1038/22659

10. Fu L, Pelicano H, Liu J, Huang P, Lee CC. The circadian gene period 2 plays an important role in tumor suppression and DNA damage response in vivo. Cell (2002) 111:41-50. doi:10.1016/S0092-8674(02)00961-3

11. Fulda S, Gorman AM, Hori O, Samali A. Cellular stress responses: cell survival and cell death. Int J Cell Biol (2010) 2010:214074. doi:10.1155/2010/214074

12. Albrecht U, Zheng B, Larkin D, Sun ZS, Lee CC. MPer1 and mper2 are essential for normal resetting of the circadian clock. J Biol Rhythms (2001) 16:100-4. doi:10.1177/074873001129001791

13. Chappuis S, Ripperger JA, Schnell A, Rando G, Jud C, Wahli W, et al. Role of the circadian clock gene Per2 in adaptation to cold temperature. Mol Metab (2013) 2:184-93. doi:10.1016/j.molmet.2013.05.002

14. Gardner PR, Nguyen DD, White CW. Aconitase is a sensitive and critical target of oxygen poisoning in cultured mammalian cells and in rat lungs. Proc Natl Acad Sci U S A (1994) 91:12248-52. doi:10.1073/pnas.91.25.12248

15. Gardner PR, Raineri I, Epstein LB, White CW. Superoxide radical and iron modulate aconitase activity in mammalian cells. J Biol Chem (1995) 270:13399-405. doi:10.1074/jbc.270.22.13399

16. Zhang Q, Piston DW, Goodman RH. Regulation of corepressor function by nuclear NADH. Science (2002) 295:1895-7. doi:10.1126/science.1069300

17. Williamson DH, Lund P, Krebs HA. The redox state of free nicotinamide-adenine dinucleotide in the cytoplasm and mitochondria of rat liver. Biochem J (1967) 103:514-27.

18. Chretien D, Benit P, Chol M, Lebon S, Rotig A, Munnich A, et al. Assay of mitochondrial respiratory chain complex $\mathrm{I}$ in human lymphocytes and cultured skin fibroblasts. Biochem Biophys Res Commun (2003) 301:222-4. doi:10.1016/S0006-291X(02)03016-4

19. Klement P, Nijtmans LG, Van den Bogert C, Houstek J. Analysis of oxidative phosphorylation complexes in cultured human fibroblasts and amniocytes by blue-native-electrophoresis using mitoplasts isolated with the help of digitonin Anal Biochem (1995) 231:218-24. doi:10.1006/abio.1995.1523

20. Wenk J, Brenneisen P, Wlaschek M, Poswig A, Briviba K, Oberley TD, et al. Stable overexpression of manganese superoxide dismutase in mitochondria identifies hydrogen peroxide as a major oxidant in the AP-1-mediated induction of matrix-degrading metalloprotease-1. J Biol Chem (1999) 274:25869-76. doi:10.1074/jbc.274.36.25869

21. Macip S, Igarashi M, Fang L, Chen A, Pan ZQ, Lee SW, et al. Inhibition of p21-mediated ROS accumulation can rescue p21-induced senescence. EMBO J (2002) 21:2180-8. doi:10.1093/emboj/21.9.2180

22. Sambrook J, Fritsch EF, Maniatis T. Molecular Cloning: A Laboratory Manual. New York, NY: Cold Spring Harbor Laboratory (1989).

23. Reed LJ, Muench H. A simple method of estimating fifty percent endpoints. Am JHyg (1938) 27:493-7.

24. Balsalobre A, Brown SA, Marcacci L, Tronche F, Kellendonk C, Reichardt HM, et al. Resetting of circadian time in peripheral tissues by glucocorticoid signaling. Science (2000) 289:2344-7. doi:10.1126/science.289.5488.2344

25. Park SY, Chang I, Kim JY, Kang SW, Park SH, Singh K, et al. Resistance of mitochondrial DNA-depleted cells against cell death: role of mitochondrial superoxide dismutase. J Biol Chem (2004) 279:7512-20. doi:10.1074/jbc.M307677200

26. Srinivas P, Gopinath G, Banerji A, Dinakar A, Srinivas G. Plumbagin induces reactive oxygen species, which mediate apoptosis in human cervical cancer cells. Mol Carcinog (2004) 40:201-11. doi:10.1002/mc.20031

27. McCord JM, Fridovich I. Superoxide dismutase. An enzymic function for erythrocuprein (hemocuprein). J Biol Chem (1969) 244:6049-55.

28. Troyano A, Sancho P, Fernandez C, de Blas E, Bernardi P, Aller P. The selection between apoptosis and necrosis is differentially regulated in hydrogen peroxidetreated and glutathione-depleted human promonocytic cells. Cell Death Differ (2003) 10:889-98. doi:10.1038/sj.cdd.4401249

29. Keston AS, Brandt R. The fluorometric analysis of ultramicro quantities of hydrogen peroxide. Anal Biochem (1965) 11:1-5. doi:10.1016/0003-2697(65) 90034-5

30. Epling CL, Stites DP, McHugh TM, Chong HO, Blackwood LL, Wara DW. Neutrophil function screening in patients with chronic granulomatous disease by a flow cytometric method. Cytometry (1992) 13:615-20. doi:10.1002/cyto. 990130609

31. Tsujimoto Y. Cell death regulation by the bcl-2 protein family in the mitochondria. J Cell Physiol (2003) 195:158-67. doi:10.1002/jcp.10254

32. Nakahata Y, Sahar S, Astarita G, Kaluzova M, Sassone-Corsi P. Circadian control of the NAD+ salvage pathway by CLOCK-SIRT1. Science (2009) 324:654-7. doi:10.1126/science.1170803

33. Ramsey KM, Yoshino J, Brace CS, Abrassart D, Kobayashi Y, Marcheva B, et al. Circadian clock feedback cycle through NAMPT-mediated NAD+ biosynthesis. Science (2009) 324:651-4. doi:10.1126/science.1171641

34. Rutter J, Reick M, Wu LC, McKnight SL. Regulation of clock and NPAS2 DNA binding by the redox state of NAD cofactors. Science (2001) 293:510-4. doi:10.1126/science. 1060698

35. Oster H, Yasui A, van der Horst GTJ, Albrecht U. Disruption of $m$ Cry2 retores circadian rhythmicity in mPer2 mutant mice. Genes Dev (2002) 16:2633-8. doi:10.1101/gad.233702

36. Merrow M, Roenneberg T. Circadian clocks: running on redox. Cell (2001) 106:141-3. doi:10.1016/S0092-8674(01)00443-3

37. Bellet MM, Orozco-Solis R, Sahar S, Eckel-Mahan K, Sassone-Corsi P. The time of metabolism: NAD+, SIRT1, and the circadian clock. Cold Spring Harb Symp Quant Biol (2011) 76:31-8. doi:10.1101/sqb.2011.76.010520

38. Hardeland R, Coto-Montes A, Poeggeler B. Circadian rhythms, oxidative stress, and antioxidant defense mechanisms. Chronobiol Int (2003) 20:921-62. doi:10.1081/CBI- 120025245

39. Johnson CH. Endogenous timekeepers in photosynthetic organisms. Annu Rev Physiol (2001) 63:695-728. doi:10.1146/annurev.physiol.63.1.695

40. Liu FQ, Zhang JR. X-ray induced L02 cells damage rescued by new anti-oxidant NADH. World J Gastroenterol (2003) 9:1781-5.

41. Asher G, Lotem J, Cohen B, Sachs L, Shaul Y. Regulation of p53 stability and p53-dependent apoptosis by NADH quinone oxidoreductase 1. Proc Natl Acad Sci U S A (2001) 98:1188-93. doi:10.1073/pnas.98.3.1188

42. Filipski E, King VM, Li X, Granda TG, Mormont MC, Claustrat B, et al. Disruption of circadian coordination accelerates malignant growth in mice. Pathol Biol (2003) 51:216-9. doi:10.1016/S0369-8114(03)00034-8 
43. Berns K, Hijmans EM, Mullenders J, Brummelkamp TR, Velds A, Heimerikx M, et al. A large-scale RNAi screen in human cells identifies new components of the p53 pathway. Nature (2004) 428:431-7. doi:10.1038/nature02371

44. Miki T, Matsumoto T, Zhao Z, Lee CC. P53 regulates Period2 expression and the circadian clock. Nat Commun (2013) 4:2444. doi:10.1038/ncomms3444

45. Hua H, Wang Y, Wan C, Liu Y, Zhu B, Yang C, et al. Circadian gene mPer2 overexpression induces cancer cell apoptosis. Cancer Sci (2006) 97:589-96. doi:10.1111/j.1349-7006.2006.00225.x

46. Oda A, Katayose Y, Yabuuchi S, Yamamoto K, Mizuma M, Shirasou S, et al. Clock gene mouse period 2 overexpression inhibits growth of human pancreatic cancer cells and has synergistic effect with cisplatin. Anticancer Res (2009) 29:1201-9.

47. Sun CM, Huang SF, Zeng JM, Liu DB, Xiao Q, Tian WJ, et al. Per2 inhibits k562 leukemia cell growth in vitro and in vivo through cell cycle arrest and apoptosis induction. Pathol Oncol Res (2010) 16:403-11. doi:10.1007/s12253-009-9227-0

48. Yoshida K, He PJ, Yamauchi N, Hashimoto S, Hattori MA. Up-regulation of circadian clock gene Period 2 in the prostate mesenchymal cells during flutamideinduced apoptosis. Mol Cell Biochem (2010) 335:37-45. doi:10.1007/s11010009-0238-7

49. Luo Y, Tian W, Cai L, Wang Y, Zhang J, Teng H, et al. Expression profiling reveals a positive regulation by mPer 2 on circadian rhythm of cytotoxicity receptors: Ly49C and Nkg2d. Chronobiol Int (2009) 26:1514-44. doi:10.3109/ 07420520903553435

Conflict of Interest Statement: The authors declare that the research was conducted in the absence of any commercial or financial relationships that could be construed as a potential conflict of interest.

Received: 19 November 2014; accepted: 19 December 2014; published online: 13 January 2015.

Citation: Magnone MC, Langmesser S, Bezdek AC, Tallone T, Rusconi S and Albrecht $U$ (2015) The mammalian circadian clock gene Per 2 modulates cell death in response to oxidative stress. Front. Neurol. 5:289. doi: 10.3389/fneur.2014.00289

This article was submitted to Sleep and Chronobiology, a section of the journal Frontiers in Neurology.

Copyright (c) 2015 Magnone, Langmesser, Bezdek, Tallone, Rusconi and Albrecht. This is an open-access article distributed under the terms of the Creative Commons Attribution License (CC BY). The use, distribution or reproduction in other forums is permitted, provided the original author(s) or licensor are credited and that the original publication in this journal is cited, in accordance with accepted academic practice. No use, distribution or reproduction is permitted which does not comply with these terms. 